\title{
PERINATAL SUPLEMENT WITH L-METHYLFOLATE FOR THE TREATMENT AND PREVENTION OF DEPRESSION
}

\section{Q BACKGROUND}

Depression is a major public health priority that represents the leading cause of disability worldwide. More than 300 million people of all ages suffer from this mental disorder, that affects more women than men.

Perinatal depression is a common condition with significant adverse maternal, fetal, neonatal, and early childhood outcomes. It is defined as minor or major episodes of depression occurring during pregnancy or the first postpartum year. In developing countries, about $15.6 \%$ women experience this mental disorder during pregnancy and $19.8 \%$ after child birth (WHO).

Maternal depression is treatable. Between the various modalities of treatment, a new discovery in the field of nutrition included the neurochemistry and the function of the brain, coining the name Nutritional Psychiatry, was reported, considering that certain nutrients are important in the neurotransmission system and pregnancy depletes essential nutrients.<smiles>CN1c2c([nH]c(N)nc2=O)NCC1CNc1ccc(C(=O)N[C@@H](CCC(=O)O)C(=O)O)cc1</smiles>

\section{Q OBJECTIVES}

Several nutrients have been examined in relation to their contribution to prevention and management of depression.

This non-systematic literature review analyzes the nutritional supplement L-methylfolate, the active form of folic acid, as a promising add-on agent for acute treatment of depressive disorder and for depressive relapse prevention in women planning or during pregnancy.

\section{Q METHODS}

Data was obtained through an internet-based literature search, using the following keywords: depression; perinatal depression; maternal health; nutrition; folic acid; L-methylfolat.

The search used mainly the databases PubMed, Elsevier and NCBI. The World Health Organization was also utilized.

\section{Q RESULTS}

Individuals deficient in folic acid present psychological symptoms, particularly depressive symptoms and impaired cognitive functioning. Compared to healthy controls, individuals with depression had lower serum and red blood cell folic acid levels. Folic acid can be used as a supplement for enhancing pharmaceutical treatment, or even on its own, to treat individuals with depression, who have borderline low or deficient folic acid levels.

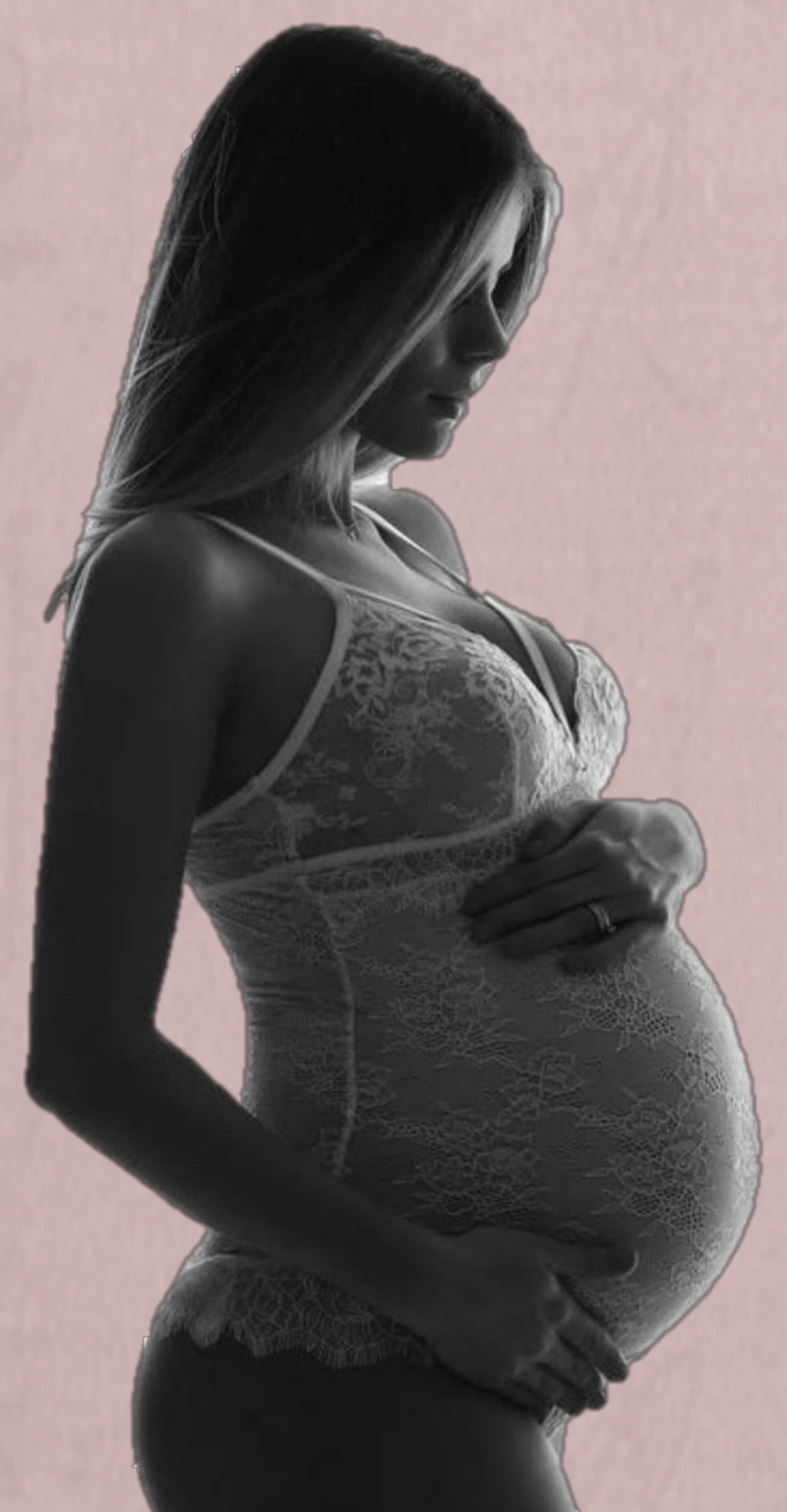

\section{Q CONCLUSIONS}

Depression in pregnancy is a common condition but is underreported as it's symptoms are often attributed to the pregnancy itself. The use of antidepressants non-teratogenics is recommended, in addition to the implementation of nonpharmacological treatment such as nutritional supplements.

Literature suggested L-methylfolate supplementation as a well-tolerated intervention with potential efficacy for prevention and treatment of perinatal depression.

Despite accumulating evidence for the relation between folic acid and mood disorders, the existing evidence is not yet sufficient to infer a causal direction.

\section{REFERENCES}

World Health Organization (2018). Depression; World Health Organization (2019). Maternal mental health. Scheffta C, Kilarskib LL, Bschorc T, Köhlera S (July 2017). Efficacy of adding nutritional supplements in unipolar depression: A systematic review and meta-analysis.

Bender A, Hagan K, Kingston N (July 2017). The association of folate and depression: A meta-analysis.

Lazarou AC, Kapsou M (2010). The role of folic acid in prevention and treatment of depression: An overview of existing evidence and implications for practice.

Freeman MP, Savella GM, Church TR, Góez-Mogollón L, Sosinsky AZ, Noe OB, Kaimal A, Cohen LS (February 2019). A prenatal supplement with methylfolate for the treatment and prevention of depression in women trying to conceive and during pregnancy.

Alhusen JL, Alvarez C, (May 2016). Perinatal depression.

\section{AUTHORS}

Peta J. ${ }^{1}$, Albuquerque $\mathrm{M}^{2}$, Caldas $\mathrm{I}^{1}$, Moreno $\mathrm{M}{ }^{1}$.

${ }^{1}$ Centro Hospitalar Psiquiátrico de Lisboa, Psychiatry, Lisboa, Portugal.

${ }^{2}$ Hospital de Cascais, Psychiatry, Cascais, Portugal. 